\title{
REACCIONES SOCIOSANITARIAS DERIVADAS DEL MIEDO A LA MUERTE DURANTE LA PRIMERA PANDEMIA DE CÓLERA A SU PASO POR PLASENCIA EN 1834
}

\author{
Socio-Health Reactions Derived from the Fear of Death \\ during the First Cholera Epidemic of the 19th Century
}

\author{
Daniel Leno González \\ dleno@unex.es \\ Universidad de Extremadura. España
}

Fecha de recepción: 18/09/2020

Fecha de aceptación: 25/04/2021

RESUMEN: Desde su origen endémico en los deltas del Ganges y el Indo, el cólera se extendió de manera pandémica durante oleadas sucesivas a lo largo del siglo XIX. Su llegada iba precedida de un miedo generalizado por diversos factores, aparatosidad de síntomas, el sentido impredecible de su marcha, pero sobre todo por su desconocimiento etiológico y terapéutico. El siguiente trabajo trata de analizar el miedo durante la primera aparición de la enfermedad en España. Más concretamente se analizan los imaginarios en materia de salud de los individuos o colectividades, conformadores de la cultura sanitaria predominante en la sociedad y la comprensión a partir de ellos, de los comportamientos, en este caso de los cuidadores y autoridades. Para ello se diseña un estudio histórico-sociocultural, utilizando varias fuentes etnográficas sobre las que se aplica el método de la «tipología del discurso».

Palabras clave: miedo; cuidadores; epidemias; cólera.

ABSTRACT: From its endemic origin in the deltas of the Ganges and the Indo the cholera spread in a pandemic way during successive waves throughout the 19th century. His arrival was preceded by a widespread fear for various factors, apparatusity of symptoms, the unpredictable sense of his departure, but above all for his etiological and therapeutic ignorance. The following work tries to analyze the fear during the first appearance of the disease in Spain. More specifically, the imaginary 
ones are analyzed in the matter of health of the individuals or collectivities, conformers of the predominant health culture in the society and the understanding from them, of the behaviors, in this case of the caregivers and authorities. For this, a historical-sociocultural study is designed, using various ethnographic sources on which the method of «speech typology» is applied.

Keywords: fear; caregivers; epidemics; cholera.

Sumario: 1. Introducción. 2. Desarrollo. 2.1. Fuentes documentales. 2.2. Resultados. Discusión. 3. Reflexión final. Conclusiones. 4. Fuentes primarias. 5. Referencias bibliográficas.

\section{INTRODUCCIÓN}

A lo largo del siglo XIx, la viruela, en el plano internacional, y la fiebre amarilla, en el caso de España, fueron sustituidas por el cólera. Esta enfermedad, endémica de ciertos países asiáticos, se desbordó sobre Europa en el segundo cuarto de siglo a través de cuatro oleadas sucesivas que convirtieron la endemia en auténtica pandemia. En 1833 se produce la primera epidemia en la Península Ibérica; Portugal primero y España después sufrirán el primer contagio del siglo, para entonces el desconocimiento etiológico y terapéutico era total, motivo por el cual se presentaba como enfermedad nueva, terrible, y de consecuencias nefastas. Plasencia fue una de las ciudades en las que se detectó de una forma temprana la preocupación por el riesgo del contagio. La Junta Local de Sanidad pronto se hizo eco de las noticias que llegaban de Portugal, iniciando con ello un auténtico despliegue de prevenciones.

Es inevitable que el imaginario colectivo reaccione, ante una situación de emergencia sanitaria, a partir de una de las emociones morales más básicas: el miedo. Y que este se contagie más extensamente, persista más tiempo y cause más daño que las infecciones biológicas. En nuestra memoria cultural colectiva permanecen una serie de epidemias que la humanidad sufrió y sobrevivió.

En los contextos epidémicos la muerte ha estado muy presente y amenazaba con hacerse realidad inmediata en cualquier sujeto. Todos pensaban que podían morir. La muerte era presentada intrínsecamente a todos. Al mismo tiempo que las sociedades terminaban normalizando su impacto fatal, ella se colectivizaba y se convertía en pasto de políticos y clérigos, todos ellos en busca de una clientela que atraer aprovechando la conmoción psicológica del momento (Beltrán Moya, 2006).

En el terreno de la prevención y de los métodos empleados para poner coto a la enfermedad, si bien es cierto que los sistemas comunitarios e individuales de aislamiento eran conocidos y se pusieron en práctica en una primera parte, en el momento de la llegada del cólera no existió una verdadera política sanitaria estatal. Esta no llegaría hasta finales de la primera mitad del siglo XIX, como señala Vicente Pérez Moreda (2013), «la política de higiene y sanidad públicas en el ámbito nacional se había ido desarrollando gracias a la acumulación de experiencias obtenidas 
en ocasiones similares de tiempos anteriores, con motivo de la peste de mediados del siglo XVII».

Aún hoy en día, el miedo al contagio de una epidemia sigue siendo uno de los resortes emocionales más poderosos en la sociedad contemporánea. Pero, desde luego, el miedo es irracional y desencadena toda una gama de reacciones exacerbadas, desde la incredulidad hasta la paranoia y la agresividad, e incluso a la segregación y rechazo social. La reacción discriminadora impulsada por el miedo más primario y primitivo, el miedo a enfermar y morir, parece natural y hasta cierto punto inevitable. La discriminación hacia otros que deriva de este miedo es, desde el punto de vista ético, siempre condenable. Por ello debe ser contrarrestada, y todo uso simbólico y político de este miedo proscrito, dado que estigmatiza a todo un grupo poblacional o étnico, y lo pone en situación de vulnerabilidad político-social, además de la posible biológica que efectivamente sufra.

El cólera está considerado clásicamente como la última de las grandes enfermedades epidémicas que asolaron occidente, pero independientemente de su importancia objetiva (o sea, medida en términos demográficos y económicos), lo que nadie pone en duda es la relevancia subjetiva que la presencia de la enfermedad epidémica alcanzó en las comunidades afectadas. El cólera fue, en todo lo largo del siglo XIX, sentido como una amenaza gravísima, por la aparatosidad de su cuadro clínico, la ausencia de un tratamiento eficaz y el sentido impredecible de su marcha, características todas que se encontraron exacerbadas con motivo de la primera pandemia (en Europa, 1829-1837).

El impacto editorial de dicha enfermedad, junto con la persistente presencia de la misma, han contribuido a formar la memoria histórica, en nuestra cultura, del cólera como enfermedad terrorífica y de importancia trascendental en nuestro desarrollo científico-social. Sin embargo, dentro del panorama historiográfico español sobre el cólera, la primera pandemia fue la menos atendida. Posiblemente por dificultades heurísticas (parquedad y escasa fiabilidad de los datos oficiales existentes; dispersión, pérdida o difícil acceso de fuentes documentales, etc.). En este sentido, hay que destacar que son escasos los informes impresos en su momento por las Academias de Medicina. Los investigadores que en España se han interesado por esta epidemia, en algunos casos, han podido localizar otros en copia manuscrita original, habiendo permanecido inéditos, según nuestros conocimientos, desde 1834 hasta la fecha.

La mayoría (por no decir todos) los trabajos sobre el cólera destacan la presencia de ese miedo (en algunos se destaca incluso sus repercusiones sociales y culturales), al que hay que atribuirle un origen no tanto en su impacto demográfico, sino más bien en la aparatosidad de sus manifestaciones clínicas, a las que se habrían de sumar los rituales religiosos en torno a la muerte.

Se hace necesario definir el miedo como emoción primaria, pero ¿qué es una emoción?. En palabras de Mora Teruel, en su más simple pronunciamiento, 
la emoción es ese motor que todos llevamos dentro, una energía que nos mueve y viene codificada en circuitos neuronales específicos del cerebro. Las emociones refieren a los mecanismos inconscientes que utiliza el individuo para sobrevivir y comunicarse. Por eso las emociones y el lenguaje emocional están entrelazados en lo más profundo y primitivo del ser humano. Como indica la etimología de la palabra emoción, esta quiere decir "movimiento hacia afuera», es decir, un acto de conducta que puede ser producido por un estímulo procedente del mundo externo o interno (memoria) del individuo. De esta manera la reacción conductual inconsciente de miedo es una emoción innata, universal, que poseen casi todos los animales y se expresa máximamente en los mamíferos, incluido el hombre. Está producida por una amenaza, un peligro para la supervivencia o evocada por el recuerdo de tales peligros y amenazas. En el hombre, esta emoción, gracias al cerebro y los mecanismos que generan la conciencia, se eleva a sentimiento. Es un sentimiento desagradable y, dependiendo de su intensidad, puede llegar a ser de terror, pánico y hasta paralizante. El ser humano siempre tiene una emoción de miedo básico en su conducta, desde que se levanta hasta que se acuesta. Con la autoconciencia nacieron nuevos miedos que fueron solo y genuinamente humanos. Los miedos sociales, los miedos de vivir con los demás, los miedos a los otros (Mora Teruel, 2015). El miedo puede también bloquear nuestras facultades, llevarnos a decisiones erróneas, o responder a peligros imaginarios y convertirse en obsesivo. ¿Puede constituir incluso un elemento crucial en la cultura de un determinado periodo histórico? (Delumeau, 1978).

\section{DESARROLLO}

Cualquier enfermedad, cualquier epidemia, solo adquiere sentido e importancia dentro de un contexto humano por las formas en que se infiltra en la vida de sus gentes, por las reacciones que provoca y por el modo en que da expresión a los valores culturales y políticos de una época determinada, que trata de enfrentarse colectivamente a aquella. La propia etimología de la palabra griega epidemos (sobre el pueblo) confirma plenamente esta idea (Beltrán Moya, 2006).

Tratando de definir claramente el objeto de estudio de este trabajo, podemos decir que se trata de indagar en la cultura sanitaria, es decir, actitudes, comportamientos, percepciones y construcciones-representaciones sociales generadas, desentrañar la maraña de significados, símbolos, comprender las reglas, normas, ideas y creencias que subyacen y rigen los comportamientos. De esta manera, y como objetivo general de esta investigación, se pretende analizar el miedo a la muerte en los cuidadores, autoridades y población en general, y como específicos, determinar las diferentes estrategias de supervivencia mental que llegó a generar en la sociedad, el análisis de los imaginarios en materia de salud de los individuos o colectividades, 
conformadores de la cultura sanitaria predominante en la sociedad y la comprensión a partir de ellos, de los comportamientos, no solo de los cuidadores, sino también de las diversas autoridades.

\subsection{Fuentes documentales}

Se trata de un estudio cualitativo de corte histórico. El tipo de investigación realizada es histórico-sociocultural con diseño transversal, utilizándose para su desarrollo varias "fuentes etnográficas» y aplicando sobre ellas el método historiográfico utilizado por el profesor Diego Peral y conocido como «la tipología del discurso», consistente en aplicar un método de análisis del discurso a un corpus formado por textos de carácter legislativo-sanitario. Evidentemente, no dispongo de una máquina del tiempo que me sitúe en esos años del siglo XIX, ni conozco a nadie que viviera entonces, y mucho menos que fuera miembro de la Junta de Sanidad Municipal, por ejemplo. Por lo que la revisión de fuentes documentales como las actas de dicha Junta (A. J. M. S), las actas capitulares (A. C.), Reales Órdenes (R. O.), Boletín Oficial de la provincia (B. O. P.), Boletín de Medicina Cirugía y Farmacia (B. M. C. F.), etc., me van a permitir realizar una etnografía histórica, presentando un escenario teatralizado, directo, una representación de un aquí y ahora específico. Me va a permitir, además, "escuchar voces diferentes», apreciar dudas y vacilaciones, alcanzar, en definitiva, un acompañamiento insonoro del discurso, aunque privándome de ese "puesto de honor» del que disfruta todo etnógrafo: el poder ser partícipe activo e in situ de la escena que pretendo investigar.

Con la realización de este estudio histórico-sociocultural se trata de comprender la realidad social y cultural de los cuidadores y autoridades en un determinado momento histórico protagonizado por la llegada de una nueva enfermedad. Entraría dentro de la vía de análisis que Revel y Peter (1980) llamaron «sociología de la enfermedad». En esta, los historiadores han tratado de incorporar categorías que les permitieran entender la presencia de la enfermedad en diferentes sociedades. Desde la sociología de la enfermedad se evalúa el papel de las instituciones sanitarias, los procesos de marginación y segregación de los enfermos pobres; asimismo, aspectos socioeconómicos, desempleo y alimentos, etc. En estudios así se intenta revelar el efecto de la presencia de la peste, de las enfermedades epidémicas o de las cotidianas; no obstante, no solo se hace desde el punto de vista cuantitativo, sino tratando de encontrar el significado de las distintas conceptualizaciones acerca de lo que eran las enfermedades. Estos son modelos de investigación mórbida, en los cuales se diversifica el enfoque y se intenta integrar los datos de esta sociología de la enfermedad con un análisis más rico. Ejemplos de este tipo de investigaciones los tenemos en: Lebrun, 1971; Bardet, 1983; Oliver, 1986, y Pérez Moreda, 1980.

Al trabajar «la tipología del discurso» podemos decir que la propuesta fundamental del presente artículo es aplicar al material consultado un método de análisis 
que pretende conocer la base conceptual que subyace en la manifestación discursiva del texto. Método descrito por el profesor del departamento de historia de la Universidad de Extremadura Antonio Rodríguez de las Heras y su grupo de investigación (Rodríguez de las Heras, 1987), y utilizado por Peral Pacheco (como se apunta más arriba). Dentro de este trabajo no es posible abordar con la extensión requerida el fondo teórico y todo el desarrollo metodológico, pero sí resulta imprescindible hacer una breve descripción del método para que quede mejor explicado el análisis.

En palabras de Peral Pacheco, el método permite la formulación de una ideología como una estructura de conceptos. El discurso de un texto en su discurrir va mostrando, a través de las palabras, los conceptos unos detrás de otros en una manifestación lineal, sin que el lector pueda tener la visión de conjunto de los conceptos que allí se encierran. La formulación de los conceptos del discurso es el paso previo para poder establecer la estructura ideológica del discurso. El método de análisis de las estructuras ideológicas ha sido aplicado preferentemente en distintos ensayos sobre textos históricos (Peral Pacheco, 1994).

La propuesta (y concretando al máximo) en este trabajo básicamente es utilizar este artificio para esclarecer si el pensamiento médico-científico del momento y el conocimiento sobre la enfermedad que se estudia (escaso entonces), intervienen como moldeadores de la percepción subjetiva sobre la enfermedad, si esta a su vez genera miedo y si este se transforma en motor de reacciones sociales exacerbadas.

Entramos en el mundo de la ideología y mentalidad, y la diferencia entre una y otra la podíamos establecer en que mientras la primera es un pensamiento rico en conceptos que de alguna manera al recorrer el discurso nos muestra una gran variedad de ideas encerradas en esos conceptos, la segunda se debate en una pobreza de ideas, que en muchos casos son las únicas que se dan en el discurso de forma muy repetitiva. La ideología, pues, se define como la organización conceptual de las ideas, de un pensamiento. La unidad mínima en una ideología sería, por tanto, la relación entre, al menos, dos conceptos, puesto que un concepto se reconoce, se interpreta, gracias a la relación con los demás. Esa relación puede ser positiva (si ambos conceptos se complementan) o negativa (si se niegan), en este último caso serían dos conceptos antagónicos. Explico con un ejemplo: si descendemos al terreno del "laboratorio" y tomamos dos conceptos (salud y huida) como la estructura más simple, podemos explicar mejor el método. Para su expresión formal, estos dos conceptos, complementarios en algunos textos, vendrán expresados en esta ideología a través de un vector que señala el concepto que en esa ideología se considera hacia dónde va el discurso. La lectura de esa relación sería «la huida es el mejor específico para la salud».

En cuanto a las fuentes históricas y bibliográficas para esta investigación se han consultado testimonios literarios, crónicas históricas, textos legislativos, así como libros escritos por médicos de la época, y que se detallan en el apartado destinado 
a la bibliografía. De la misma manera, la España que padeció este primer azote del siglo entre 1832 y 1836, más concretamente, la ciudad de Plasencia entre 1832 y 1835, se presenta como el ámbito espacial y temporal del análisis.

Las múltiples manifestaciones locales han dado materia a innumerables y repetitivas monografías descriptivas (Alcalá Ferráez, Angolotti Cárdenas, Ayala Pérez, Clemente Fuentes, Delange, Merinero Martin, Puerto Sarmiento, Rodríguez Flores, o Rodríguez Ocaña, por citar solo algunos) que presentan la enfermedad como un mal casi apocalíptico, que desestructura la realidad social por la que pasa, reflejando distintas manifestaciones de tipo simbólico.

\subsection{Resultados. Discusión}

En 1832 se publican las instrucciones, que sobre medidas de prevención fueron dictadas por la Comisión Central del Consejo de Sanidad, y aprobadas por la Prefectura de Policía de París. Estas fueron traducidas al castellano por Superior Disposición con las modificaciones necesarias por las costumbres, necesidades y situación específica de los españoles. En ellas se hace referencia al cólera como enfermedad grave, pero no obstante se realiza la advertencia de que es mayor el miedo que causa el esperarla, que el riesgo que se corre cuando existe. $Y$ al compararla con otras enfermedades epidémicas, tales como las viruelas, la escarlatina, y ciertas fiebres nerviosas, destaca el hecho de que estas han hecho más estragos en las regiones de Europa donde ha reinado el cólera, destacando el hecho de que, aun cuando hubieran sido muy favorables las circunstancias a su propagación, únicamente fue atacado un individuo sobre 75 , y aún en algunas ciudades la proporción fue solamente de un individuo sobre 200 (Biblioteca Nacional de España. Instrucción Popular formada por la Comisión Central del Consejo de Sanidad y aprobada por la Prefectura de Policía de París).

En la España del año 1833 las noticias que llegaban sobre la gravedad de los efectos del cólera motivaron una alarma (¿miedo?) tan grande como la que antes había acompañado a las mortíferas epidemias de fiebre amarilla o de peste. Como entonces, el principal recurso preventivo de las autoridades fue la disposición de barreras a la libre comunicación, tanto por vía marítima como terrestre. Toda la normativa desplegada en este momento se orienta sobre todo a intensificar el control sociopolítico. El contagio era uno de los temas obligados y constituye ahora la cuestión más debatida tanto en el terreno político como en el científico. No solo la normativa, también la prensa, tanto política como médica, recoge un ingente número de artículos que versaban sobre esa temática y en los que se vertían numerosas teorías, muchas de ellas contradictorias entre sí. Ello nos da una idea de lo poco claras que estaban las cosas al respecto (Clemente Fuentes, 2008). El Gobierno, en un principio, parece aceptar las teorías contagionistas. Era lo más cómodo, ya que permitía con ello establecer los tradicionales mecanismos antiepidémicos 
(acordonamientos sanitarios y cuarentenas), los cuales, además, le permitían ejercer actividades represivas. De no haber aceptado el carácter contagioso del morbo, las medidas tendentes a la supresión de los focos de insalubridad, al aumento del nivel de vida y a la mejora de los saneamientos que hubiera debido aplicar, según postulaban las teorías miasmáticas o ainticontagionistas, le habrían resultado, aparte de más costosas, bastante más difíciles de llevar a cabo (Puerto y San Juan, 1980).

De esta manera se ponen en marcha medidas que enlazan tres conceptos complementarios en el texto (empirismo, incomunicación y salud). Las medidas de aislamiento mediante la utilización de cordones sanitarios, estando de acuerdo con el doctor Peral Pacheco en el sentido de representar una rudimentaria forma de lucha contra la enfermedad, separaban claramente la profilaxis de la etiología, que por otra parte aún era totalmente desconocida. Está claro que no se quería oír a la comunidad científica en torno a este asunto. En el Informe de Mateo Seoane quedaba meridianamente claro: "los cordones generales sanitarios son poco útiles cuando los contagios son débiles y pueden hacerse epidémicos, sin embargo si el mal está limitado, es posible establecerlos» (Seoane, 1834). El gobierno, no estando poseído de gran eficacia en sus resultados, estableció los cordones sanitarios quizás para minimizar y tranquilizar los ánimos de la población, la cual por otra parte, según Sámano, no se mostraba del todo conforme: «murmura el pueblo de todo cuanto cree ser gravamen por más que le traiga los más positivos bienes» (González de Sámano, 1858). Estas medidas de aislamiento, desde el punto de vista epidemiológico las podríamos incluir dentro de lo que pudiera ser el control de determinantes de factores medioambientales, impidiendo un acercamiento entre el reservorio (aunque en 1833 se desconocía) y el sujeto sano susceptible. Los determinantes dependientes de factores medioambientales son un amplio conjunto de factores que tienen como común denominador ser externos al individuo y que, en general, no pueden ser manipulables por este en sentido individual; aunque de manera grupal una comunidad o sociedad humana puede interaccionar tan decisivamente en ellos que los condicione, pasando el propio modelo social y su desarrollo tecnológico a convertirse por sí mismos en determinantes medioambientales de la salud de sus individuos (Ferreiro Ardións, 2012).

Analizando la tipología del discurso en una primera relación y motivado por el miedo se presentan dos conceptos básicos: salud e incomunicación, pudiéndose afirmar además desde la lectura de textos legislativos que serían complementarios porque se extrae que "la incomunicación conservaría la salud» (Peral Pacheco, 1994). A las autoridades les preocupa la salud de la población, sí, pero más aún la aparición de conflictos sociales, que pudieran derivar de situaciones de pánico o miedo, ya que toda la normativa desplegada en este momento se orienta sobre todo a intensificar el control sociopolítico. Desde esta primera relación por ser la primera medida adoptada por la Corona, el discurso a lo largo de 1833 y hasta la mitad de 1834 recorre otros conceptos de tal manera que va ampliando esta 
estructura básica en lo que sería una red de conceptos presentes en los textos y con relación ya sea positiva o negativa entre ellos que o bien refuerce los dos básicos o al contrario los niegue.

El jueves 12 de junio de 1834 en el Boletín de Medicina, Cirugía y Farmacia se hacía referencia a la existencia del cólera en Andalucía, Extremadura y Murcia, de las dudas de su propagación por contacto y por tanto de la eficacia y utilidad de los cordones sanitarios: "Según las noticias que tenemos, y que confirman los datos oficiales publicados, el cólera ha aparecido casi simultáneamente en infinitos puntos de la vasta extensión de las Anadalucías, Extremadura, Mancha y reino de Murcia, si bien no es tan matador como el que reinó en el año próximo pasado. Estas dos circunstancias, que ya se han observado en varias ocasiones, nos hacen dudar de la propagación del cólera por contacto (o lo que es lo mismo, de su propiedad contagiosa), y de la eficacia y utilidad de los cordones sanitarios. Acordémonos de que para penetrar en Viena, traspasó siete de estos cordones, y antes de afligir a los pueblos con una medida tan llena de inconvenientes, meditemos bien y procuremos convencernos de su necesidad y utilidades» (B. M. C. F., 12 de junio de 1834). Y desde primeros de julio, ante la situación que está creando el cólera en España, el gobierno comienza a mostrarse sensible ante las presiones sociales, reconoce el resultado dañino y perjudicial que la incomunicación produce en los pueblos «infectos y sospechosos». Este nuevo discurso de la Corona muestra un cambio en el terreno de las ideas sobre el cólera, admitiendo los funestos resultados de las medidas de incomunicación, perdiendo estas fuerza para defender la salud. También se empiezan a traducir publicaciones de monografías extranjeras, que detallaban la experiencia en la lucha contra el cólera en lugares como Londres, París, Moscú, etc.; y en ellas se detalla la ineficacia de cordones y cuarentenas: «que había cometido un error, adoptando las incómodas y más que inútiles medidas de cordones y cuarentenas contra el cólera» (Gillrrest. 1834). La Corona española no perdería de vista a Europa, pues para ella es «la cabeza de la civilización» y, viendo la ineficacia de los cordones sanitarios, en Real Orden de 24 de agosto de 1834 disuelve los que se habían establecido en España. De esta manera, el discurso cambia su recorrido, abandonando un concepto capital del mismo hasta ahora como era la incomunicación. Reconociendo la Corona la inutilidad de los cordones sanitarios y evidenciando los perjuicios económicos para los pueblos, esta se digna escuchar a la Junta Suprema de Sanidad del Reino, y en consecuencia actuar disolviendo y eliminando todas las medidas de aislamiento. Se ha fracasado en mantener la salud a través de la incomunicación, pero más aún se ha alterado la concepción que sobre el contagio se tenía, es decir, entendido este como el modo de transmisión, se pusieron en marcha medidas de aislamiento que a la postre han resultado inútiles y más aún perjudiciales. Esto hace que la relación complementaria que existía entre empirismo e incomunicación se muestre ahora antagonista. La serenidad que se buscaba en el pueblo, la no aparición de conductas de pánico (¿miedo?), se ha 
traducido ahora y por la incomunicación en hambre y miseria. Fueron los médicos los que se erigieron en portavoces del sentir popular y en todas partes trataron de convencer a las autoridades de la inutilidad y perjuicio de los cordones sanitarios (Orta Rubio, 1984). Rodríguez Ocaña considera que este cambio de actitud por parte de los médicos españoles frente al cólera, en tanto que teóricos de la patología, estuvo determinado principalmente por factores socioeconómicos:

En un momento en que la medicina carecía de medios objetivos para garantizar el diagnóstico, enfrentándose distintas posiciones en torno a la etiología del cólera, parece evidente, a tenor de los testimonios reflejados, que el peso de las consideraciones sociales arrastró en una determinada dirección las teorías médicas, de manera que la original creencia universal (en España) acerca de la contagiosidad del cólera (años 1831-32) se pasó a la negación rotunda de dicha postura. Significativamente, dicha posición teórica se alcanzó de la mano de la inutilidad de las medidas coercitivas sanitarias en la prevención del cólera, medidas ampliamente rechazadas por sus tremendas repercusiones socioeconómicas. Puede afirmarse que la parte importante de la agitación o campaña contra las medidas de incomunicación fue obra de médicos llevados de consideraciones eminentemente no médicas. (Rodríguez Ocaña, 1981).

Por otra parte, se presentaba también como motivo nada desdeñable del impacto psicológico del anuncio de la existencia del cólera en España, la escasa concordia observada entre los médicos europeos respecto de la terapia más idónea, así como el escaso resultado obtenido por todas ellas. Como señala el aventurero Falp, desde Polonia: «...Esta fue verdaderamente una época de anarquía para la terapéutica, en que cada uno recetaba lo primero que le pasaba por la imaginación». Falta de acuerdo, pues, por un lado: el número de planes o métodos curativos prácticamente igualó al de facultativos que atendieron la enfermedad. Uso extensivo de remedios por otro hasta el punto de que: «...fuera preciso la enumeración de toda la materia médica para contar los medios empleados contra esta enfermedad...» (Rodríguez Ocaña, 1982). La verdad es que contra esta nueva enfermedad no existía remedio conocido para combatirla, había una falta de precedentes que hacía volver la vista hacia la divinidad o al saneamiento de las costumbres. Una vez instaurada la enfermedad, curarla era prácticamente imposible, por lo que la terapéutica se encaminaba al control de la sintomatología. No se contaba más que con los medicamentos tradicionales para recibir al nuevo azote (Peset y Peset, 1972). De esta forma, algunos médicos recomendaban la quinina, el opio, las hierbas aromáticas, como la salvia, tila y menta, los ácidos minerales y vegetales, los productos nitrados y las sales neutras. Otros se decantaban por medicamentos estimulantes que combatiesen la relajación y el debilitamiento del cuerpo enfermo. Incluso sería conveniente evitar, en opinión de algunos, pasiones deprimentes. Y no faltaban prestigiosos galenos que proponían maravillosos remedios a base de alcanfor, calomelanos, sal de cocina, acíbar y borraja, en lavativas, fricciones y tostadas, y remojado todo 
en aguas y alcoholes salados, sedativos y alcanforados (Sánchez de la Calle, 1994). Por tanto, la falta de acuerdo en las causas y los mecanismos de acción, por un lado, y el limitado arsenal terapéutico, por otro (esta es la época que se ha denominado "edad heroica» de la medicina), se conjugaron en un lamentable espectáculo de confusión, donde cada cual reclamó para su método las mayores virtudes (Rodríguez Ocaña, E. 1983).

Algunos vecinos pertenecientes a los estratos más destacados abandonaban las poblaciones huyendo de la posibilidad de invasión. Este tipo de actuación era una práctica común por parte de los individuos más destacados, los cuales en cuanto una epidemia asolaba o amenazaba, con todo tipo de pretextos, huían al campo o a otras localidades donde el peligro de invasión fuera inexistente. Este fue el caso por ejemplo del chantre de la Catedral de Plasencia Juan Antonio Lucio, quien dejó la ciudad según él "por asuntos de salud y familiares» (Leno González, 2015). Y es que la enfermedad colérica tenía tendencia clasista, pues respetaba más a los individuos de los estratos superiores de la sociedad, mientras se ensañaba con los inferiores. Vemos en esta huida una nueva manifestación del miedo, siendo la salida de las poblaciones una de las recomendaciones en 1832 y 1833 (y por tanto dos conceptos complementarios: huida y salud) pero no en 1834, aun así aunque en escaso número, en lugares atacados se produjeron casos de abandono, llegando noticias al Gobierno que algunos facultativos de medicina y cirugía, faltando a los deberes más sagrados de su profesión, y quebrantando el juramento que prestaron para poder ejercerla, abandonaron los pueblos de su residencia en los momentos en que debían ser más necesarios sus servicios, pues de su presencia y auxilio dependía acaso la vida de sus conciudadanos. Desde luego esta actitud de aquellos que estaban obligados a asistir y cuidar a los enfermos resultaba del todo intolerable, ya que su trabajo era determinante para el control del estado sanitario de las poblaciones. Un caso concreto lo tenemos en la ciudad de Plasencia y el abandono de su cirujano titular, Esteban Planas, quien expuso como causa de su marcha la necesidad de resolver asuntos importantes en su ciudad de origen, Barcelona. Este fue uno de los numerosos casos que se produjeron en España. La Corona mediante Real Orden de 4 de julio de 1834 no permitió que tan cobarde actitud quedase impune y como tal estableció severas penalidades, como por ejemplo la inhabilitación para seguir ejerciendo la medicina o cirugía:

El interés público y el honor mismo de la facultad exigen que tan criminal conducta no quede impune, y que los nombres del corto número de profesores que por vergonzosa cobardía los mancharon de esta manera, no se confundan con los demás médicos españoles, que tanto se han distinguido siempre y se distinguen en la actualidad por repetidos rasgos de filantropía, por celo y noble emulación con que disputan las victimas a la enfermedad que aflige a varios pueblos y por la noble ambición de sorprender a la naturaleza el secreto de su curación. (R. O., 4 junio 1834). 
Sería lícito ver también en la «huida» de facultativos una nueva respuesta coherente del miedo. De cualquier modo, en estos comportamientos habría que diferenciar el abandono por precaución (propio de las clases pudientes y que se producía antes de la llegada de la enfermedad y con un destino definido), del abandono por desesperación, que llegaría a producirse en masas, sin rumbo y ante la posibilidad de ser rechazados en otros pueblos. Hecho este último que se pudo comprobar cómo se produjo en 1833, cuando eran rechazados si no procedían de lugares sanos.

Analizando el discurso se puede apreciar cómo se va produciendo un cambio en los conceptos que da a aquel un recorrido inestable. Si en un principio se aceptó la huida como comportamiento para preservar la salud, ambos conceptos se presentan complementarios, ahora al añadir otros como médicos y filantropía, presentan a estos como indispensables para defender la salud y la Corona además para estimular la moral de los facultativos premiará a los mismos. Aparecen por tanto en los extremos del discurso y ante una situación crítica el honor o la deshonra, la entrega en el cuidado o la huida ante el miedo a la muerte.

Pero entrando en el terreno de los cuidados, se establecieron Casas de Socorro, donde se ofrecían los primeros auxilios y hospitales de coléricos. Las primeras en algunos sitios eran consideradas meras casas de observación, o lazaretos (diferentes a aquellos donde el sospechoso debía pasar cuarentena), custodiadas por militares, y en las que la incomunicación con el exterior debía ser absoluta. En las enfermerías de estas casas se encerraban un médico, un sangrador, que hacía las veces de practicante, un enfermero, un cocinero y un sacerdote para la asistencia espiritual. La tropa cuidaba de que ni estas personas ni los enfermos tuvieran el menor contacto con el exterior, mandándose partes diarios que tenían que ser dejados en librillos con vinagre colocados a cierta distancia de la casa. Para el caso de la llegada del Cólera-Morbo a Plasencia, dentro de los planes asistenciales trazados por las autoridades locales, y teniendo como fin una rápida atención a las personas aquejadas del mal y eliminar el "foco de infección» que pudiera representar la existencia de enfermos de cólera, vivos o muertos en viviendas insalubres, en el verano de 1833 (un año antes de declararse la enfermedad oficialmente en la ciudad) ya se buscaba un hospital de curación. Y será el antiguo Hospital de la Merced el elegido para prestar a los enfermos los cuidados necesarios:

Considerando la Junta muy preciso preparar un edificio que sirva de Hospital de curación para los enfermos que se hallen atacados de la terrible y fatal enfermedad del cólera-morbo, si por desgracia llegan a manifestarse en esta ciudad, habiendo conferenciado con la debida meditación se convenció de que no hay otro edificio más acomodado y capaz que el hospital llamado de Na Sa. de la Merced. Y como tal lo señaló para hospital de curación en su respectivo caso, previniendo que se pase el oficio más atento al M.N. y L Ayuntamiento, como patrono de dicho hospital para que se sirva prestarle para el servicio explicado. (Archivo Municipal de Plasencia. Actas de la Junta Municipal de Sanidad. Sesión de 13 de septiembre de 1833). 
Cuando el cólera llega a Plasencia un año después, serían tres los hospitales (si consideramos a la enfermería de los padres descalzos como parte del hospital de la Cruz) que habrían de atender a los enfermos de cólera: hospital de Santa María, hospital de la Merced y hospital de la Cruz. No se determinó entonces la adecuación de un hospital para coléricos (como sí se hizo el año anterior), pero sí se destinaron salas independientes dentro de los propios hospitales para atender únicamente a enfermos de cólera-morbo: «...habiendo sido atacada de cólera-morbo fue asistida en el hospital de Santa María donde está destinada la sala para coléricos» (Archivo Parroquial de Santa María. Libro de finados).

Al tiempo que se incrementa el miedo entre la población crecerán los oportunistas y los remedios milagrosos. Fenómeno habitual durante todas las epidemias de cólera del XIX y buena muestra de las creencias populares, alimentadas sin duda por la ineficacia médica. Se trataría de remedios empíricos de no más dudosa efectividad que los propuestos por los médicos. Muchos enfermos debían ser cuidados en sus propios domicilios, por lo que existió un miedo exagerado y la creencia en un gran peligro de contagio entre las personas que deberían asistir a los enfermos atacados del mal. Para minimizarlo Seoane (médico que convivió y trató la enfermedad en Inglaterra) asevera que el peligro es mucho menor del que se corre «asistiendo a los enfermos de cualquier tabardillo grave», y recalca el corto número de facultativos y enfermeros que proporcionalmente han sufrido el cólera en todas partes tras el contacto con el enfermo, "a pesar de que en algunas, por ejemplo Inglaterra, no se han tomado casi nunca, ni aún las precauciones más sencillas que deberían tomarse en todos los casos de epidemia». Será necesario adoptar una serie de precauciones en las casas donde se cuide al enfermo: adecuada ventilación en toda la casa, pero principalmente en el aposento donde está el enfermo. Jamás se le deberá cuidar en alcobas o cuartos que no dispongan de comunicación directa e inmediata con el aire exterior y a la luz, y a ser posible en salas que dispongan de chimenea o estufa, "pues se podrá entonces mantener la ventilación haciendo fuego en ellas, cuando el estado del tiempo no permita tener abiertas las ventanas o vidrieras". Escrupulosa limpieza en los cuartos de los enfermos, suelos, paredes, ropa, vasos, etc. Pero, además, en los rincones del cuarto se aconsejaba poner vasijas chatas y muy anchas llenas de la solución del cloruro de cal, que se tendría cuidado de menear varias veces al día; se podrían también colgar trapos empapados en la misma solución en varias partes del aposento, y aún se echaría una porción de ella en los servicios luego que se laven. Las personas que asistan a los enfermos debían no hacer excesos en la comida o bebida, observando con esmero la limpieza personal. Sería necesario además impedir que se visite a los coléricos por solo curiosidad, salvo aquellas personas encargadas del cuidado, quienes serán las autorizadas para entrar en las habitaciones, "pues independientemente de otras consideraciones, la experiencia ha probado que hay más peligro en tener accidentalmente comunicación con un colérico, que el asistirle en su enfermedad, así como también ha 
probado no pocas veces cuan perniciosa puede ser la impresión repentina que produce en muchas personas el cambio extraordinario que se suele observar en la cara de los coléricos». En las casas donde hubiese muerto algún enfermo se tomarían las siguientes precauciones: será necesario regar el cadáver y el aposento donde esté con la solución del cloruro. En cuanto a la ropa, aquella que haya servido al enfermo se empapará también en solución de cloruro de cal, la restante se colgará en un cuarto que se calentará lo más que sea posible y debajo de ella se pondrán vasijas con aquella solución para que reciba los vapores. Enseguida se podrá lavar la ropa que no se pudiese echar a perder, mojándola en agua caliente, bastando con tender al sol y al aire libre la que no pudiese lavarse. Las paredes del cuarto se blanquearán con cal, y la cama, particularmente si es de madera, se deberá también lavar con solución de cloruro (Seoane, 1834).

Estudiando el discurso de Mateo Seoane, por tanto, el miedo al contagio no debería ser un concepto que quedase formulado en el mismo, porque la idea de la transmisión directa de cuerpo enfermo a sano, o lo que es lo mismo, el contagio interpersonal, era considerado por el autor como muy limitada. De la misma manera, la Real Orden de 24 de agosto de 1834, al igual que en el discurso de Seoane, recoge la Higiene, constituyéndose esta en el arma preventiva, además apoyada en la ciencia se encamina como una lucha contra la insalubridad. Lo aportado por la ciencia (en este caso Mateo Seoane) y lo escrito en este texto legislativo, nos induce a pensar, por tanto, que el mecanismo de transmisión por el que creen se da el cólera en este momento es la atmósfera, impidiendo que se den esas condiciones especiales que provocarían la enfermedad. No se observa en este momento, sin embargo, acción directa sobre el reservorio principal, es decir, el ser humano, responsable además de uno de los dos mecanismos de transmisión más importantes, la vía fecal-oral, que va provocando poco a poco la progresión del contagio hasta la vía hídrica responsable de los brotes epidémicos. Lógicamente, en esta primera pandemia, tanto el reservorio humano como ambas vías de transmisión eran desconocidas, y dentro de esas recomendaciones que se describen más arriba apenas alguna pudiera haber sido parcial e indirectamente efectiva, y que son las que se orientan hacia la contaminación aérea eliminando contenidos para que ni se vieran ni se olieran, pero que no evitarían en definitiva que restos contaminados en deposiciones se filtraran hacia puntos de abastecimiento, al no existir una correcta eliminación de excretas y que en último lugar no se habría actuado correctamente sobre este eslabón de la cadena epidemiológica.

Esta tranquilidad y por tanto alejamiento de situaciones de miedo que persigue transmitir Seoane en su monografía a las personas que asisten a los enfermos, es similar a la que se recibe de la experiencia con la enfermedad en otros países. Dentro de la controversia contagiosidad-anticontagiosidad, en aquellos lugares que precedieron a España en la convivencia con la enfermedad, los detractores del carácter contagioso del cólera publicaban en sus escritos diversas evidencias de médi- 
cos, familiares, enfermeras, etc., que no contrajeron el mal tras el contacto con los enfermos. En Moscú, por ejemplo, se contaba que ni los familiares de enfermos de cólera que atendieron a los pacientes en sus casas ni las enfermeras que les visitaban contrajeron la enfermedad, ni tampoco los médicos que usaron por ejemplo la misma agua que había servido de baño a los enfermos:

La convicción ya asegurada de que la comunicación con los enfermos no aumenta el riesgo, debiera disminuir de aquí en adelante el temor que inspira ésta enfermedad (el cólera), la cual a diferencia de la peste, no quita al doliente toda esperanza de ser socorrido, ni destruye todos los vínculos de parentesco y el afecto. De ahí en más, los que fueren atacados no carecerán de auxilios y consuelos, y la separación o remoción a un hospital, causa de desesperación, no vendrá ya a aumentar el peligro a los asistidos en lo futuro sin que uno tema por sí mismo ni por aquellos con quienes vive. (Gillrrest, 1834).

La comisión enviada al extranjero para estudiar el curso de la enfermedad, reflejaría al respecto en su informe que:

Los enfermeros y enfermeras vivían y dormían en las mismas salas de los enfermos, sin más separación que la de sus cortinas, les daban las friegas, les ayudaban a levantarse, les arreglaban la cama y se veían continuamente ensuciados con la materia de sus deyecciones etc. pues no obstante, en todo el tiempo que nosotros visitamos los hospitales (estío y otoño de 1832), no vimos que un solo enfermero contrajese el cólera. (Sánchez Núñez, 1834).

En el Boletín de Medicina Cirugía y Farmacia para tranquilizar a los cuidadores también se reflejaría en varias ocasiones las pocas posibilidades de contagio:

...En efecto, por punto general, como dice el Dr. Falp, se ha notado que los individuos empleados en el servicio de los enfermos durante esta epidemia, que son los más expuestos a la influencia de los miasmas, han sido menos acometidos que los demás. En Moscow en el hospital de Ordinka solo una enfermera entre diez y seis contrajo la enfermedad, y fue a consecuencia de un enfriamiento repentino; que en los hospitales se practicaron ensayos muy expuestos; que no se adoptaron por la mayor parte de profesores y dependientes medidas preservativas; que se despreció en fin el riesgo del contagio y que los que así se condujeron y sus familias no tuvieron el menor mal. (...) En los hospitales de Varsovia (Polonia) en donde las salas destinadas a los coléricos bajas y privadas de ventilación contenían de sesenta a ochenta enfermos, y en donde los practicantes y mozos tenían que permanecer día y noche respirando sin cesar aquella atmósfera viciada; y en donde se sirvieron a menudo de las camisas, sábanas y cubiertas acabadas de quitar de las camas y cuerpos de los enfermos y cadáveres, no hubo más que un caso de cólera que fue un enfermero de una sala a cargo del Dr. Foy 
que falleció a las seis horas de invadido; pero aún este accidente fue determinado por haberse embriagado fuera del hospital poco antes de la invasión según confesión del finado. (B. M. C y F. Jueves 9 de octubre de 1834).

Sin embargo, la anterior postura, aunque mayoritaria, no era mantenida por todos, aunque fueran también partidarios de un origen miasmático o atmosférico. Tal es el caso del Dr. Francisco Purrúa, que detalla su experiencia derivada del contacto con los enfermos en Sevilla durante la epidemia de 1833:

Prescindiendo de Triana, de cuyos enfermos nada puedo decir con seguridad, repito que en los otros arrabales baratillo, Cestería etc., no se presentó el mal hasta que vino al primero el estivador de lana con la misma enfermedad que habían padecido algunos de la tripulación del buque inglés; y no se propagó en dichos arrabales, sino por las comunicaciones, que no cesaron entre los sanos y éste primer enfermo (...). Más adelante se extendió por dentro de los muros de Sevilla, habiendo influido en ello las mismas causas: lo que demuestra que los enfermos son otros tantos focos capaces de transmitir o comunicar el mismo mal a los individuos que le rodean, aunque no se pongan en contacto inmediato; pues la observación ha enseñado que personas sin roce de ninguna especie con los inválidos fueron acometidos de la enfermedad, y más digo, hasta los animales la contrajeron a veces en las casas en que había entrado ya; lo cual prueba que el agente propagador es un miasma sutilísimo, capaz de que le sirva de vehículo la atmósfera que circunda al paciente. (Porrúa y Velázquez, 1834).

El colectivo médico, a través de su Boletín, a primeros de julio de 1834 informa de las características que deben reunir los hospitales que para la atención a los enfermos coléricos se establezcan en las poblaciones. Para ello recomienda una ubicación en parajes bien ventilados, así como evitar el hacinamiento de enfermos por considerarlo foco de infección, por tanto, se prefiere un mayor número de hospitales con pocos enfermos en cada uno:

Deben establecerse hospitales efectivamente en parajes ventilados, pero no deben ser grandes ni situarse muy lejos de la población. El número excesivo de enfermos, aun de males no sospechosos, y su hacinamiento dan lugar a la producción de emanaciones y miasmas que constituyen focos de infección. Si los hospitales se sitúan lejos, tienen el inconveniente de hacerse inútiles para los infinitos enfermos que llegan a la hora extrema: la rapidez del cólera en su curso, y la ineficacia de los auxilios no dispensados en el principio de la invasión, reclaman la formación de hospitales en todos los cuarteles, y aún mejor en cada barrio, siempre que los medios pecuniarios lo permitiese. (B. M. C y F. 10 de julio de 1834).

Aparecen, como vemos en estos últimos párrafos, nuevos conceptos formulados en el discurso, por ejemplo, la ventilación como un medio que entra dentro de la higiene para luchar contra la insalubridad, y sobre todo se aprecia ya en esta 
primera epidemia la existencia de un cierto miedo a que la agrupación de enfermos vicie el aire, haciéndose hincapié entonces (dentro de ese cuidado y vigilancia de las condiciones higiénicas) en los efectos perjudiciales del hacinamiento.

\section{REFLEXIÓN FINAL. CONCLUSIONES}

Sin ánimo de redundar, sino muy al contrario, queriendo centrar las conclusiones, un objetivo general y claro era el origen de este trabajo: el análisis de los imaginarios en materia de salud de los individuos o colectividades, conformadores de la cultura sanitaria predominante en la sociedad y la comprensión a partir de ellos, de los comportamientos, en este caso de los cuidadores y autoridades. En este contexto, el concurso de las fuentes analizadas me permiten concluir que:

- Las características del cólera en esta su primera presentación se consideran como determinantes importantes de la reacción popular que suscita en general y entre los cuidadores de los enfermos en particular, es decir, aspectos tales como la novedad o familiaridad, la violencia, la incidencia geográfica y social, los síntomas de la enfermedad y secuelas, el desconocimiento etiológico y terapéutico, la percepción del riesgo, y con ella la presencia del miedo. Todo ello configura el tipo de respuesta y su intensidad.

- Una epidemia aparece marcada por varios elementos: elevado número de sujetos atacados, impotencia para enfrentar la enfermedad, muerte como peligro inmediato. Pero es que además se dan otras características de tipo social, como pueden ser la exclusión o el rechazo. No solo el individuo está enfermo, también afecta a la familia, el barrio, la provincia o la ciudad, y es esa representación social, colectiva y simbólica, a veces incluso rodeada de ritual, la que hace que aparezca el miedo y por tanto que se les tema porque implican una forma de muerte. Es posible, por tanto, que ese recuerdo de reacciones sociales exacerbadas en anteriores enfermedades (peste, viruela, etc.) llevara a las autoridades tanto políticas como sanitarias a inclinarse por las recomendaciones de tranquilidad en lo que se refiere al contacto con el enfermo (que hay que reconocer eran mayoritarias) de algunos médicos y no escuchar aquellas que defendían lo contrario.

- En la puesta en práctica de las medidas de aislamiento hemos podido asistir a una auténtica muestra de mecanismos en los que no se tiene en cuenta la voluntad de las personas para tomar decisiones conscientes que debieran estar basadas en el pleno uso de su inteligencia. El miedo aparece como auténtico elemento de anulación de esa voluntad y capacidad de la población, y cataliza automatismos de supervivencia tales como la huida. Por parte de las autoridades vemos en el aislamiento un auténtico control social, con información interesada, parcial y dirigida, con medidas de coerción extrasanitarias de tipo legislativo-punitivo. Se otorgan el poder de decir qué comportamientos son correctos y cuáles no, cercenando la 
autonomía individual, fundamentadas en teorías sin confirmar y que el trascurrir del tiempo demostrarían ser falsas.

- La primera epidemia de cólera en Plasencia constituye una circunstancia que afecta no solamente a la vida de los individuos considerados aisladamente, sino que supone una alteración profunda de la colectividad: incide en el desarrollo demográfico, perturba los abastecimientos, provoca gastos elevados, retrata demográficamente las diferencias de nivel de los grupos sociales y polariza actitudes políticas. Queda claro que la actuación higiénico-preventiva de la autoridad era absolutamente puntual y en concordancia con la aparición de la enfermedad. En este caso con la amenaza y aparición del cólera-morbo.

- La infraestructura asistencial placentina, tanto hospitalaria como ambulatoria, era insuficiente para cubrir las necesidades diarias que la aparición de una nueva enfermedad acarreaba. El repaso de lo que serían las maniobras municipales en la lucha contra la enfermedad en Plasencia, estando en consonancia con las llevadas a cabo en toda la geografía española, desde el principio pone de manifiesto una estructuración en torno a dos ejes: uno, la necesidad de control de la enfermedad desde un momento temprano, y el otro, el miedo a la propagación de un pánico injustificado o desmedido, estando presente este segundo eje durante todo el período estudiado.

\section{FUENTES PRIMARIAS}

Biblioteca Nacional de España. «Instrucción Popular formada por la Comisión Central del Consejo de Sanidad y aprobada por la Prefectura de Policía de París. Traducida al castellano (1832)». Madrid: Miguel de Burgos, impresor por S.M. de la Real Junta de Aranceles.

Archivo Municipal de Plasencia. Actas de la Junta Municipal de Sanidad. Sesión de 27 de mayo de 1832. Carpeta Junta de Sanidad.

Archivo Municipal de Plasencia: R.O. de 28 de agosto de 1833. Decretos del Rey Nuestro Sr Don Fernando VII y de la Reina su Augusta Esposa. Tomo XVIII. Madrid. 1834

Biblioteca Nacional de España. Boletín de Medicina Cirugía y Farmacia. 12 de junio de 1834. http://hemerotecadigital.bne.es/issue.vm?id=0003028004\&search= \&lang=en 
Archivo Municipal de Plasencia: R.O. de 1 de julio de 1834. Decretos del Rey Nuestro Sr Don Fernando VII y de la Reina su Augusta Esposa. Tomo XVIII. Madrid. 1834

Archivo Municipal de Plasencia: Boletín Oficial de la Provincia. Suplemento al del día 1-9-1834. Carpeta B.O.P, 1834

Archivo Municipal de Plasencia: R.O. de 24 de agosto de 1834. Decretos del Rey Nuestro Sr Don Fernando VII y de la Reina su Augusta Esposa. Tomo XVIII. Madrid. 1834

Archivo Municipal de Plasencia: R.O. de 4 de julio de 1834. Decretos del Rey Nuestro Sr Don Fernando VII y de la Reina su Augusta Esposa. Tomo XVIII. Madrid. 1834

Archivo Municipal de Plasencia. Boletín Oficial de la Provincia. 23 julio 1834.

Biblioteca Nacional de España. Boletín de Medicina Cirugía y Farmacia.10-7-1834. http://hemerotecadigital.bne.es/issue.vm?id=0003028053\&search=\&lang=en

Biblioteca Nacional de España. Boletín de Medicina, Cirugía y Farmacia. Jueves 9 de octubre de 1834. http://hemerotecadigital.bne.es/issue.vm?id=0003028227\& search=\&lang=en

Biblioteca Nacional de España. Boletín de Medicina Cirugía y Farmacia. 4 de julio de 1834. http://hemerotecadigital.bne.es/issue.vm?id=0003028044\&search= \&lang=en

\section{REFERENCIAS BIBLIOGRÁFICAS}

Alcalá Ferráez, C. R. (2008). Asistencia Sanidad y Población en la ciudad de San Francisco de Campeche, 1812-1861. Barcelona: Universidad de Barcelona.

Angolotti Cárdenas, E. (1975). Las invasiones del cólera en España. Contagionistas y anticontagionistas. Rev. San, Hig, Pibl., 49, pp. 1077-1164.

Ayala Pérez, J. (1975). Aspectos sociales de la epidemia de cólera de 1834 en Murcia. Revista Murgetana, 40, pp. 47-61. https://www.regmurcia.com/docs/ murgetana/N040/N040_005.pdf 
Bardet, J. P. (1983). Rouen aux XVII et XVIII siècles. Le mutations de un espace social. Paris: Sedes.

Beltrán Moya, J. L. (2006). Historia de las epidemias en España y sus colonias (13481919). Madrid: La esfera de los libros.

Clemente Fuentes, L. (2008). Los azotes del cólera morbo en la provincia de Cáceres durante el siglo XIX. Ars et Sapientia. Año IX.

De Ferrater, E. y Ferigle, P. (1841). Recopilación de las Leyes y Reales Disposiciones promulgadas en los años desde el 1833 hasta 1841 incluyendo las de la anterior época constitucional que han sido revalidadas. Tomo tercero. Barcelona: Imprenta de Don Ramón Martin Indar.

Delange, D. A. (1997). La epidemia de colera de 1833-34 en Málaga: La actuación de las autoridades locales. Isla de Arriarán, Revista Cultural y Científica, 10, pp. 157-178.

Delumeau, J. (1978). El miedo en occidente. Madrid: Ed Taurus.

De Paula Folch y Amich, F. (1834). Breve descripción del Cólera-Morbo Oriental que se padeció en la ciudad de Sevilla en los meses de septiembre, octubre y parte de noviembre de 1833. Barcelona: Imprenta de J. Verdaguer.

Ferreiro Ardións, M. (2012). El cólera en las transformaciones del siglo XIX en Alaval. La epidemia de 1834. Vitoria: Universidad del País Vasco.

Gillrrest. (1834). Cartas sobre el cólera-morbo. Zaragoza: Imprenta de Roque Gallifa

González de Sámano, M. (1858). Monografía histórica del cólera-morbo asiático en España. Madrid: Imp. Manuel Álvarez.

González Sámano, M. (1834). Memoria histórica del cólera-morbo epidémico, con la exposición de sus causas, síntomas, naturaleza, duración, terminaciones, pronóstico, curación, y medios de precaución. Madrid: Imprenta de Verges.

La Mare-Picquot. (1832). Observaciones sobre el cólera morbo de la India hechas en Bengala y en la Isla de Francia. Publicadas en París en 1831 por La MarePicquot. Traducidas por don Antonio Ortiz Transpena. Madrid. 
Lebrun, F. (1971). Les hommes et la mort en Anjou aux 170 et 18ㅇ siècles. Essai de demographie et de psychologie historiques. Paris: Mouton. https://doi. org/10.1515/9783111330525

Leno González, D. (2015). Cultura sanitaria en tiempos de epidemia: el cólera-morbo asiático en Plasencia (1832-1836). Universidad de Extremadura. Tesis doctoral inédita.

Mora Teruel, F. (2015). ¿Es posible una cultura sin miedo? Madrid: Alianza Editorial.

Merinero Martin, M. J. (1984). El cólera en 1834 en Cáceres. Norba, 5, pp. 235-247.

Oliver, L. V. (1986). Un verano mortal. Análisis demográfico y social de una epidemia de cólera en Guadalajara 1833. UNED. México.

Orta Rubio, E. (1984). El cólera, La epidemia de 1834 en la ribera de Nabarra. Príncipe de Viana, Año 45, n. 172, pp. 271-308.

Peral Pacheco, D. (1994). Cólera y Sanidad en las Reales órdenes de 1833 a 1835. Mérida: Asamblea de Extremadura.

Pérez Moreda, V. (2013). El miedo ante la epidemia en los tiempos modernos y contemporáneos. En El miedo en la historia (pp. 70-106). Valladolid: Universidad de Valladolid.

Pérez Moreda, V. (1980). La crisis de mortalidad en la España interior (siglos XVI$X I X)$. Madrid: Siglo XXI.

Peset, M. y Peset J. L. (1972). La Muerte en España: política y sociedad entre la peste y el cólera. Madrid: Seminarios y Ediciones.

Porrúa y Velázquez, F. (1834). Historia de la epidemia llamada cólera-morbo que ha sufrido Sevilla en el año de 1833, seguida de algunas reflexiones sobre el variado asiento, naturaleza y método curativo de esta enfermedad, y sobre la tan controvertida cuestión del contagio. Sevilla: Imprenta de D. Mariano Caro.

Puerto Sarmiento, F. J. y San Juan de la Orden, C. (1980). La epidemia de cólera en 1834 en Madrid. Madrid: Estudios de Historia Social.

Revel, J. y Peter, J. P. (1980). El cuerpo. El hombre enfermo y su historia. En J. Le Goff, P. Nora (eds.), Hacer la Historia (pp. 173-195). Barcelona: Laia. 
Rodríguez de las Heras, A. (1987). Teoría y Métodos. En Hipertexto/set.

Rodríguez Flores, M. P. (1991). Morir en Badajoz. El cólera de 1833, Medicina y Sociedad. Badajoz: Universidad de Extremadura.

Rodríguez Nilo, J. R. (1833). Noticias sobre el cólera-morbo, sus medios preservativos, primeros socorros y curación que conviene a los invadidos por él. Imp. del Diario de Sevilla.

Rodríguez Ocaña, E. (1983). El cólera de 1834 en Granada. Granada: Universidad de Granada.

Rodríguez Ocaña, E. (1982). Higiene y terapéutica anticolérica en la primera epidemia de cólera en España, 1833-1835. Asclepio, 34, pp. 71-100.

Rodríguez Ocaña, E. (1981). La dependencia social de un comportamiento científico: Los médicos españoles y el cólera de 1833-35. Dynamis, 1, pp. 101-130.

Sánchez de la Calle, J. A. (1994). Plasencia: historia y población en la época contemporánea (1800-1990). Mérida: Asamblea de Extremadura.

Sánchez Núñez, L., María Rubio, y P. De Paula Folch, F. (1834). Informe general de la comisión facultativa enviada por el Gobierno Español a observar el CóleraMorbo en países extranjeros, Remitido desde Berlín el 31 de mayo de 1833 por los profesores comisionados por S. M. Madrid: Imprenta Real.

Seoane, M. (1834). Instrucciones generales sobre el modo de preservarse del cóleramorbo epidémico, con indicaciones de su método curativo. Madrid: Imprenta D. M. Calero.

Stevens. (1834). Observaciones sobre la curación del cólera asiático. Por el Dr. Stevens. Traducidas del inglés por el Dr. D. José María Velázquez, Ayudante Director del Cuerpo de Médicos Cirujanos de la Real Armada. Madrid: Imprenta de Don Pedro Sanz.

Torres, J. M. (1833). Dictamen dado a esta Junta Superior de Sanidad, sobre las preocupaciones y método curativo que debe adoptarse para el cólera morbo indiano. Granada: Imp, del Ejército, pp. 3-4. 